\title{
Impact of skeletal complications on patients' quality of life, mobility, and functional independence
}

\author{
Luis Costa $\cdot$ Xavier Badia $\cdot$ Edward Chow $\cdot$ \\ Allan Lipton • Andrew Wardley
}

Published online: 15 August 2008

(C) Springer-Verlag 2008

\section{Erratum to: Support Care Cancer \\ DOI 10.1007/s00520-008-0418-0}

Table 2 in this paper was published in error. This questionnaire is still in development, and has not been approved by the Quality of life Group of the EORTC. The published Table shows a provisional questionnaire which has not yet been validated, and which may be subject to change before approval for use in clinical studies.
The online version of the original article can be found at: http://dx.doi. org/10.1007/s00520-008-0418-0.

\section{Costa $(\bowtie)$}

Instituto de Medicina Molecular-Lisboa, Servico de Oncologia,

Hospital de Santa Maria,

Av Professor Egaz Moniz,

Lisbon 1649-039, Portugal

e-mail: luiscosta.p@netcabo.pt

\section{Badia}

Health Economics and Outcomes Research,

Doctor Ferran 25, 2 ,

Barcelona 08034, Spain

E. Chow

Radiation Oncology,

Toronto-Sunnybrook Regional Cancer Centre,

2075 Bayview Ave.,

Toronto, ON M4N 3M5, Canada

\section{A. Lipton}

Milton S. Hershey Medical Center, Pennsylvania State University, 500 University Drive,

Hershey, PA 17033, USA

\section{A. Wardley}

Cancer Research Department of Medical Oncology,

Christie Hospital NHS Foundation Trust,

550 Wilmslow Road,

Manchester M20 4BX, UK
Table 2 Issues included in the bone metastases quality of life questionnaire

Location of pain in the:

1) back

2) $\operatorname{leg}(\mathrm{s})$ or $\operatorname{hip}(\mathrm{s})$

3) $\operatorname{arm}(\mathrm{s})$ or shoulder(s)

4) chest or ribs

5) buttocks

Pain issues
6) constant pain
7) intermittent pain
8) pain not relieved by medications
9) pain while lying down
10) pain while sitting
11) pain when trying to stand up
12) pain while walking
13) pain with activities such as bending or climbing stairs
14) pain with strenuous activity
15) pain interfered with your sleeping Other issues
16) modify your daily activities
17) felt isolated from those close to you
18) worried about loss of mobility
19) worried about becoming dependent on others
20) worried about your health in the future
21) felt hopeful your pain will get better
22) felt positive about your health 